\title{
Ocorrência de Estiagem no Rio Grande do Sul no Período de 1981 à 2011
}

\author{
Occurrence of Drought in Rio Grande do Sul \\ in the period 1981 to 2011
}

\author{
Denilson Kulman ${ }^{1}$, Janete Teresinha Reis ${ }^{2}$, Angélica Cargnin de Souza ${ }^{3}$, \\ Carlos Alberto da Fonseca Pires ${ }^{4}$ e Tania Maria Sausen ${ }^{5}$ \\ ${ }^{1,3}$ Mestrandos do Programa de Pós-graduação em Geografia e Geociências/UFSM \\ ${ }^{2}$ Pós-doutoranda, Departamento de Obras Hidráulicas, IPH/UFRGS \\ ${ }^{4}$ Professor Associado do Departamento de Geociências, UFSM \\ ${ }^{1,5}$ Instituto Nacional de Pesquisas Espaciais - INPE/Centro Regional Sul
}

\begin{abstract}
Resumo
A estiagem é um fenômeno natural, mas na presença humana vem causando enormes prejuízos socioeconômicos no Estado do Rio Grande do Sul, principalmente, no setor agropecuário. O objetivo principal desse trabalho consiste na espacialização da ocorrência de estiagem no Rio Grande do Sul, no período de 1981 a 2011, utilizando o método da Krigagem. A partir da Krigagem foram gerados três mapas divididos por décadas e um mapa do somatório dos 31 anos, além de um mapa da divisão municipal. Verificou-se que a maior ocorrência de estiagem concentra-se na porção sudoeste do Estado, visível tanto na espacialização pela divisão municipal quanto pelo zoneamento realizado por meio da Krigagem. Levando em consideração a espacialização obtida para todo o período observa-se a diminuição das áreas de grande ocorrência de estiagem no oeste do Estado e das áreas de baixa ocorrência na porção leste do Estado. Com isso, espera-se contribuir no planejamento e investimento visando à diminuição de perdas econômicas, principalmente no setor agropecuário no estado.
\end{abstract}

Palavras-chave: Estiagem, ocorrência, Krigagem, espacialização.

\begin{abstract}
The drought is a natural phenomenon, but the human presence is causing huge socio-economic losses in the state of Rio Grande do Sul, mainly in the agricultural sector. The main objective of this work is the spatialization of the occurrence of drought in the Rio Grande do Sul, in the period 1981-2011, using the Kriging method. As from the Kriging three maps divided for decades and one map of the summation of the 31 years considered were generated, besides a map drawn up using the municipal division. It was found that the higher occurrence of drought is concentrated in the southwestern portion of the state, visible both in the spatialization of the municipal division as the zoning performed through Kriging. Considering the spatialization obtained through of the Kriging for the whole period it is observed the reduction of the areas of high occurrence of drought in west of the state and of the areas of low occurrence in the eastern portion of the state. With this, we expect to contribute in planning and investment, aiming to reducing economic losses, especially in the agricultural sector in the state.
\end{abstract}

Keywords: Drought, occurrence, Kriging, spatialization. 


\section{Introdução}

O Estado do Rio Grande do Sul, historicamente vem sendo afetado por fenômenos naturais extremos. Estes fenômenos em contato com o ser humano estão causando sérios desastres naturais e suas causas estão relacionadas, principalmente, a aspectos hidrometeorológicos. Os desastres naturais mais frequentes e de maior intensidade, nos últimos anos, no Estado são as inundações, estiagens, vendavais e o granizo (REIS et al, 2012).

A estiagem é o resultado da redução das precipitações pluviométricas, do atraso dos períodos chuvosos ou da ausência de chuvas previstas para uma determinada temporada (CASTRO et al, 2003). Ela está entre os fenômenos naturais que se desenvolvem devido às características de determinada região do planeta (vegetação, clima, topografia, solo, etc), quando acontece em locais de presença humana gerando algum dano é tratado como desastre natural (KOBIYAMA et al, 2012). Sua ocorrência vem afetando a sociedade e a economia dos municípios gaúchos, atingindo principalmente o setor agropecuário, que depende muito das condições climáticas.

Segundo estudos de Gross et al, (2012) os municípios com economia voltada para o setor agrícola sofrem sérios danos em decorrência da estiagem. Este setor, economicamente é o primeiro a ser afetado, pela falta de infraestrutura de irrigação e armazenamento de água para a produção, tendo em vista que o solo mantém a umidade por um determinado período de tempo. Após estender o déficit de precipitação, o esgotamento da água do solo diminui rapidamente, por evaporação e/ ou infiltração, provocando a escassez de água.

Os impactos econômicos oriundos das estiagens geram efeito cascata. Os agricultores deixam de produzir o montante necessário para suprir a demanda do município tornando-se necessário a importação de determinados produtos de fora da área afetada, principalmente alimentos e matéria prima para indústria. Os produtores rurais se descapitalizam e diminui seu poder de consumo junto aos fornecedores de insumos. E estes, em decorrência da crise financeira, promovem o desemprego na zona urbana (GROSS et al, 2012 ; PONCE, 2014).

$\mathrm{O}$ conhecimento da recorrência e dos locais onde ocorrem os desastres naturais pode possibilitar, mediante planejamento e investimento, a redução da vulnerabilidade frente a esses eventos e evitar perdas econômicas significativas. Para tanto, a necessidade de se conhecer espacialmente quais áreas são mais susceptíveis a ocorrência de adversidades ambientais traz uma orientação para medidas mitigadoras (SAITO et al, 2011).

Estudo de Gross et al, (2012) mostra que os municípios de São Borja no oeste do Estado e Seberi ao norte tiveram 8 registros de situação de emergência em decorrência da estiagem de 2000 a 2010, isto é, tiveram o maior número de decretos de situação de emergência registrados no Estado do Rio Grande do Sul no período analisado. Já os municípios que apresentaram somente uma ocorrência de situação de emergência concentram-se, principalmente, no entorno da região metropolitana de Porto Alegre e próximo ao setor norte da Laguna dos Patos.

Vários estudos de ocorrência e espacialização de eventos climáticos têm utilizado a geoestatística, que está associada a uma classe de técnicas para analisar e inferir valores de uma variável distribuída no espaço ou no tempo (SILVA et al, 2003). Desta forma, objetiva-se a espacialização dos eventos de estiagem no Rio Grande do Sul ocorridos no período de 1981 a 2011 utilizando a geoestatística aplicando o método da Krigagem.

A geoestatística é um ramo da estatística aplicada que desenvolve e aplica modelos para representar fenômenos naturais, e suas propriedades variam em função da localização espacial e de pontos de observação (BETTINI, 2007).

Na geoestatística a questão central parte do pressuposto de que tudo está relacionado com tudo, mas o que se encontra mais próximo está mais relacionado. Assim, amostras próximas entre si tendem a ser mais semelhantes que amostras distantes entre si (BETTINI, 2007). Pois, próximo a um valor elevado, é mais provável que seja encontrado outro valor elevado do que um muito baixo (ANDRIOTTI, 2003).

Os estudos geoestatísticos sobre dados contínuos são orientados pela teoria das variáveis regionalizadas desenvolvida por Matheron. Com base nos dados de Krige, Matheron $(1963,1971)$ desenvolveu a teoria das variáveis regionalizadas considerando que uma variável regionalizada é uma função numérica com distribuição espacial. Nessa teoria Matheron afirma que um fenômeno é aleatório no sentido de que os valores das medições feitas podem variar consideravelmente entre si. Já sua característica regionalizada é evidente quando considerado que os valores das observações com que se trabalha não são completamente independentes da sua localização geográfica (ANDRIOTTI, 2003).

Para tanto, várias técnicas geoestatísticas de estimação foram desenvolvidas, entre elas a Krigagem, com a intenção de usufruir ao máximo das características dos dados amostrais ou adaptarem-se as suas limitações. O modelo genérico, em que estão baseadas estas técnicas, consiste em adicionar à média local, no ponto estimado, uma combinação linear dos resíduos calculados nos pontos amostrais vizinhos (BETTINI, 2007). Os tipos de Krigagem mais comumente utilizados são a simples, ordinária e universal.

Felgueiras (2000) esclarece que um estimador de Krigagem Ordinária utiliza médias locais ou tendências locais estimadas a partir das amostras vizinhas, ao invés de uma única média estacionária, como ocorre no algoritmo de Krigagem simples. Para tanto, optou-se em aplicar a Krigagem ordinária.

O uso dos procedimentos geoestatísticos em SIG's, baseados em modelos e técnicas de Krigagem, são importantes, por agregar informação com a introdução 
das coordenadas permitindo sua distribuição espacial, assim como a visualização da porção geográfica mais afetada por desastres naturais, com ênfase neste artigo, a espacialização da estiagem por zonas afetadas no Rio Grande do Sul, utilizando a krigagem.

\section{Metodologia}

\subsection{Procedimentos metodológicos}

Inicialmente foram coletados os dados históricos de ocorrência de estiagem dos municípios do Rio Grande do Sul junto ao GEODESASTRES - SUL do Instituto Nacional de Pesquisas Espaciais - INPE/CRS e Reckziegel (2007).

A partir da integração destes dados, gerou-se um banco de dados geográfico com as ocorrências anuais de eventos de estiagem. Para a delimitação da área de estudo utilizou-se a malha digital do IBGE (2010) onde constam os polígonos da divisão política dos municípios do Rio Grande do Sul.

Na planilha de dados, relacionados aos municípios, foram acrescentadas 35 colunas, sendo que as primeiras 31 correspondem a um ano diferente, a partir do ano de 1981 até o ano de 2011. Para os municípios que registraram uma ou mais ocorrências por ano foi atribuído o valor " 1 " e para os que não apresentaram ocorrência foi atribuído o valor " 0 ". Posteriormente realizou-se o somatório de ocorrência de estiagem para as décadas de 1981 a 1990,
1991 a 2000 e 2001 a 2010 excluindo-se o ano de 2011. Além disso, também foi realizado o somatório para o total de ocorrências de 1981 a 2011 totalizando 31 anos.

Para a Krigagem extraiu-se uma amostragem dos dados, ao qual foi selecionada a coordenada do centro de gravidade do polígono da área de cada município e atribuíram-se os valores de estiagem correspondente. A partir desse, foi possível efetuar a espacialização por krigagem dos somatórios dos eventos de estiagem para as décadas de 1981 a 1990, 1991 a 2000 e 2001 a 2010.

Para o somatório dos 31 anos, foram elaborados dois mapas com a espacialização e classificação dos eventos de estiagem, um utilizando a divisão política dos municípios e outro utilizando o método da Krigagem ordinária para fins de comparação entre os mapas resultantes.

A Krigagem ordinária e a classificação dos dados foram realizadas no software SPRING 5.2.3 e a edição final dos mapas no software ARCGis 10. Para a classificação das áreas de ocorrência de estiagem no Estado, foi utilizado o intervalo de duas classes, onde o tom mais escuro representa a classe de maior ocorrência e o mais claro o de menor ocorrência.

\subsection{Krigagem ordinária}

A análise geoestatística por meio da aplicação da Krigagem ordinária foi processada no software SPRING, seguindo os passos: geração do semivariograma, ajuste do semivariograma, validação do modelo de ajuste e

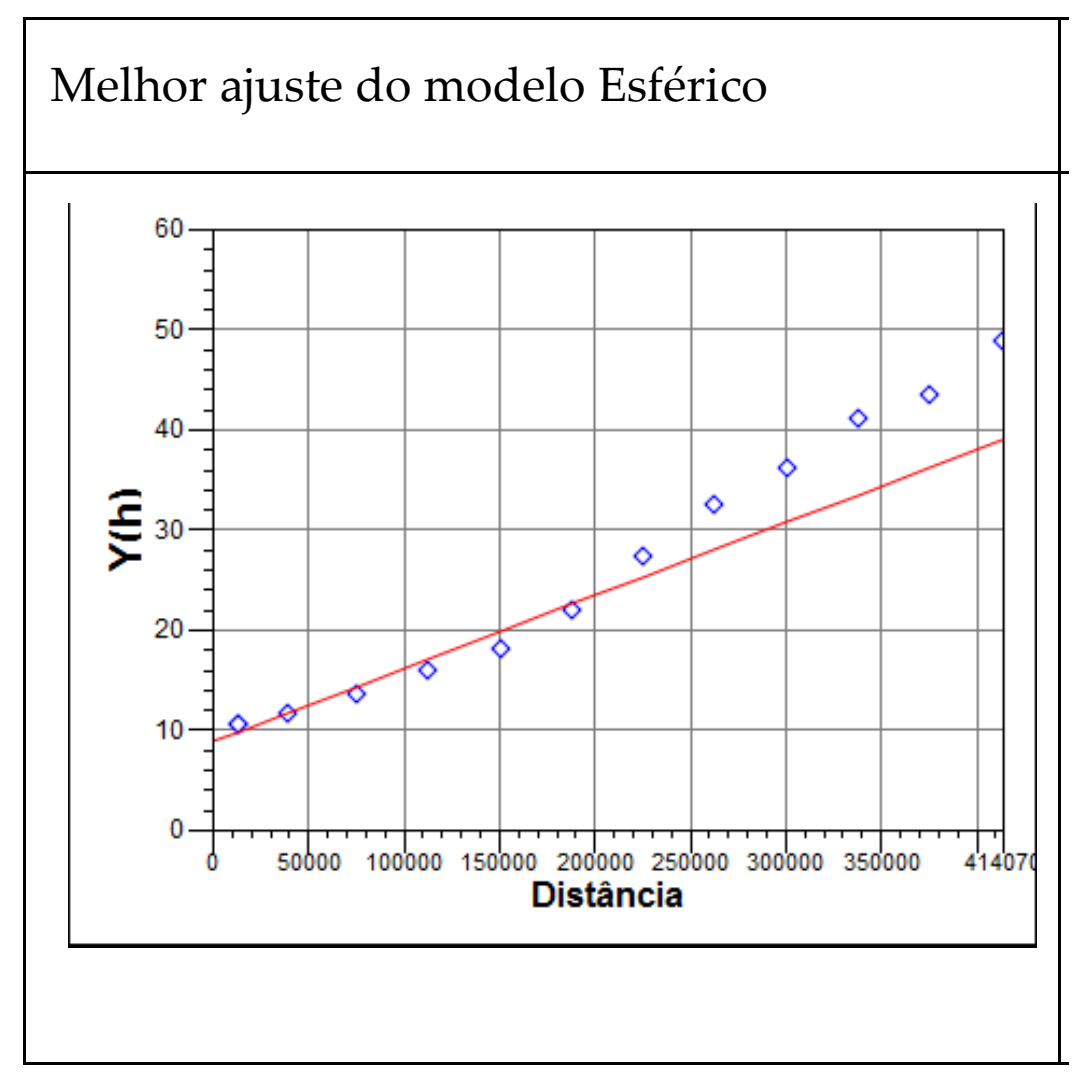

Figura 1 - Modelos geoestatísticos que melhor se ajustaram na krigagem. 


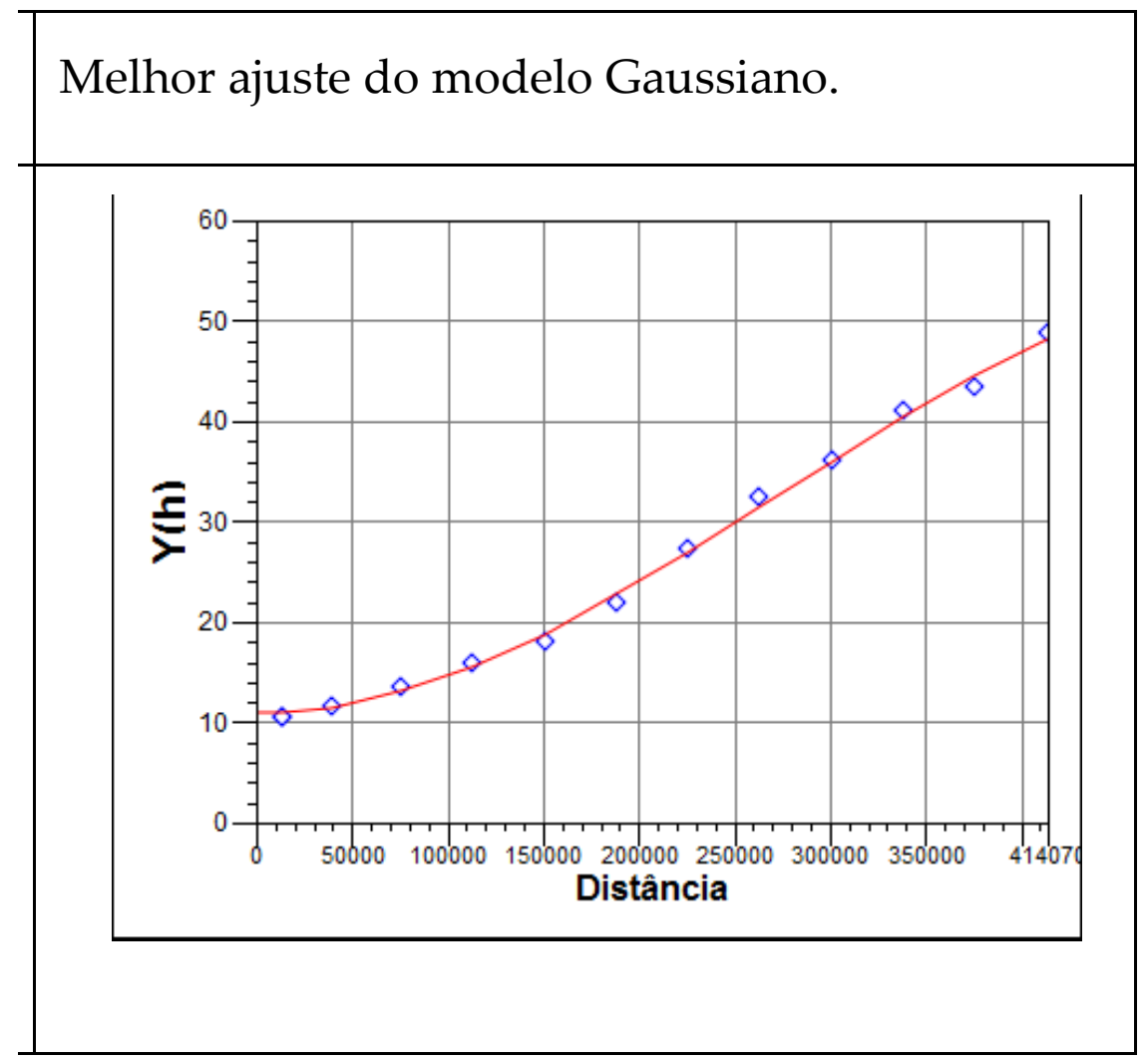

Figura 1 - continuação...

Krigagem. Na execução dos semivariogramas foi utilizada a análise unidirecional com amostragem irregular, atribuindo valores ao default para o Lag. No ajuste de direções foram testadas as seguintes, $0^{\circ}, 45^{\circ}, 90^{\circ}$ e $135^{\circ}$ e utilizadas de maior alcance para todas as Krigagens efetuadas.

Posteriormente, foi gerado o semivariograma unidirecional das amostras, o qual foi ajustado e validado. Nesta fase, se deu o ajuste dos modelos, sendo que os que melhor se ajustaram foram o esférico e o gaussiano. Porém, o modelo gaussiano apresentou melhor ajuste no modelo de superfície, conforme Figura 1.

Os parâmetros para validação do modelo foram: o efeito pepita, contribuição e alcance, valor de Akaike mais próximo de zero. A partir da validação do modelo, optou-se pela Krigagem ordinária e a utilização de 1000 por 1000 metros para a resolução. Assim, gerou-se uma malha regular e uma imagem por meio da interpolação dos pontos.

Os principais dados utilizados para a Krigagem foram:

- Década de 1981 a 1990, o ângulo de anisotropia foi de $135^{\circ}$, modelo utilizado foi o gaussiano, o efeito pepita de 0,677 , contribuição 0,459 e alcance de $273377,942 \mathrm{~m}$;

- Década de 1991 a 2000, o ângulo de anisotropia foi de $90^{\circ}$, o modelo gaussiano, o efeito pepita de 3.187, contribuição de 5,202 e o alcance de 284881,218m;

- Década de 2001 a 2010, o ângulo de anisotropia foi de $135^{\circ}$, o modelo utilizado corresponde ao gaussiano, o efeito pepita de 0,304, contribuição de 1,471 e o alcance de 288814,027m;

- Somatório dos trinta e um anos, o ângulo de anisotropia foi de $45^{\circ}$, o modelo utilizado corresponde ao gaussiano, o efeito pepita de 0,460 , a contribuição de 0,567 e o alcance de $286970,178 \mathrm{~m}$.

Como resultado obteve-se quatro imagens que foram divididos em classes que variam de 0 a 2,3 a 4,5 a 6, 7 a 8,9 a 10,11 a 12,13 a 14, 15 a 16 e 17 a 18 ocorrências, valores intermediários foram arredondados para a classe superior.

\section{Resultados}

A estiagem é um fenômeno natural que não respeita divisões políticas e os registros referentes a esse fenômeno são realizados por município.

Desta forma, a técnica da Krigagem permite um recorte espacial de áreas homogêneas dos valores resultantes por considerando que os fenômenos climáticos não obedecem limites administrativos. Por outro lado, a espacialização das ocorrências de estiagem por municípios permitem verificar pontualmente os municípios com maior e menor ocorrência de estiagem nos 31 anos analisados.

A Krigagem foi escolhida por produzir a melhor estimativa linear não viciada dos dados de um atributo, em um local não amostrado, por meio da modelagem do variograma. Já a Krigagem Ordinária por que suas estimativas são combinações lineares ponderadas dos 


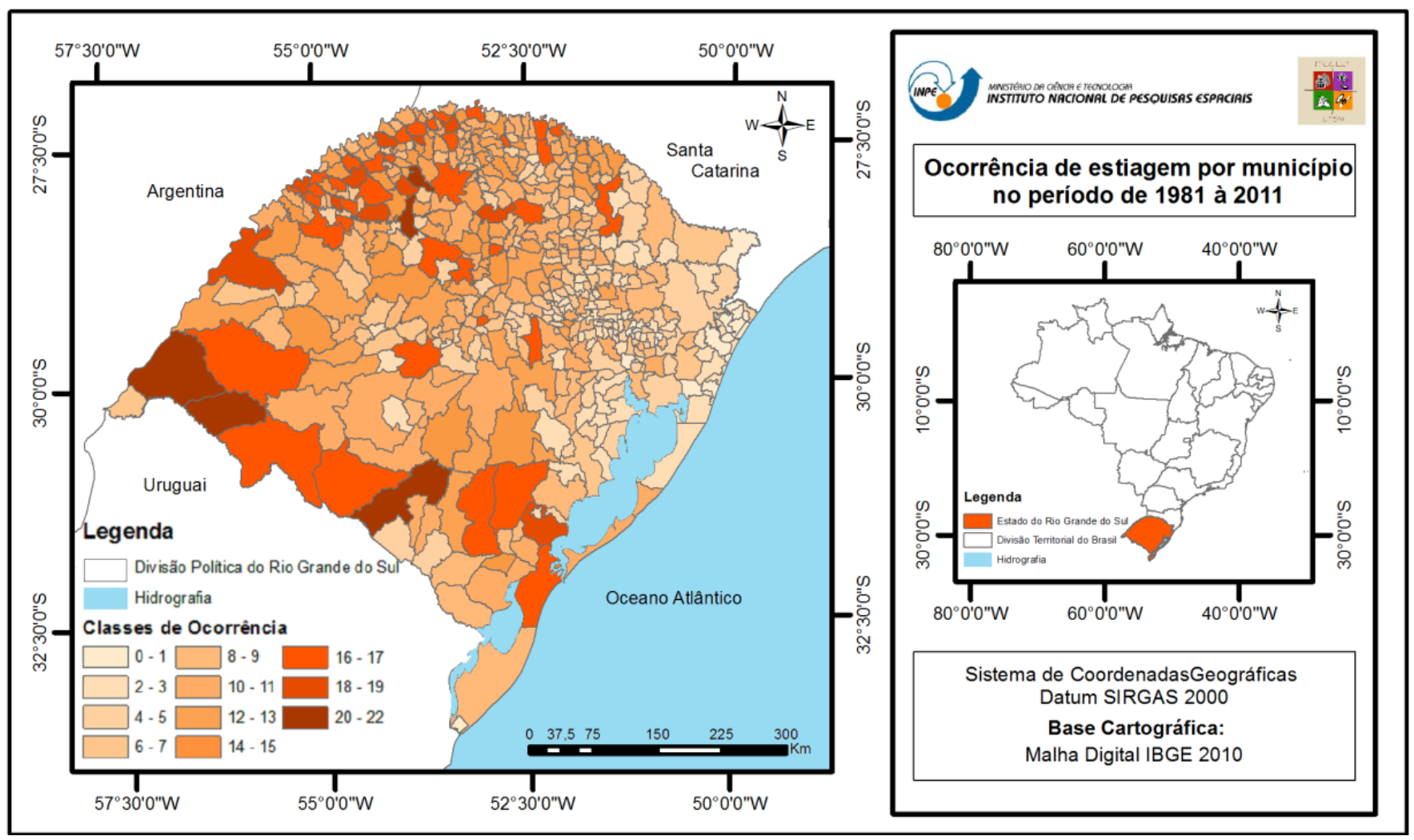

Figura 2 - Municípios com maior número de ocorrência de estiagem no Rio Grande do Sul de 1981 à 2011.

dados disponíveis, além disso, busca minimizar a variância do erro, pois a estimativa do erro esperado é nula (ISAAKS e SRIVASTAVA,1989).

A partir da espacialização das ocorrências estiagem por município, no período de 1981 a 2011, destaca-se Bagé com 22 ocorrências. Os municípios de Uruguaiana, Quaraí, Ijuí, Santo Augusto tiveram 20 registros de estiagem. Em terceira instância constatou-se que Alegrete, São Borja, Santo Augusto e Miraguaí obtiveram 19 registros de ocorrência de estiagem em 31 anos (Figura 2).

A partir do mapa resultante da Krigagem dos 31 anos (Figura 3) verificou-se que as maiores ocorrências são registradas na porção sudoeste do estado, o mesmo verificado pela espacialização por município.

No resultado apresentado pelo somatório do período de 1981 a 2011 fica evidente uma diminuição gradativa da área atingida pela estiagem no Estado. As maiores ocorrências da estiagem são basicamente no sudoeste e as menores no litoral norte (Figura 3).

A Krigagem não registra pontos isolados de ocorrência, mas a dependência espacial entre amostras vizinhas. Assim, Bagé que possui o maior número de registros permanece entre as classes maiores (Figura 3), porém, não a maior em virtude de sua vizinhança que apresenta valores inferiores ao referido município. Com isso observa-se que Bagé se situa na classe de 13 a 14 ocorrências.

Na primeira década (Figura 4) as maiores ocorrências se concentram em torno de sete a oito eventos, tornando a porção sudoeste a grande área afetada, assim como a porção de terra entre a Laguna dos Patos e a Lagoa Mirim.

A área de menor ocorrência de estiagem localiza-se no litoral norte e na porção norte do Estado, bem como no rebordo do Planalto Sul Riograndense e Depressão Central seguindo também até a metade da Laguna dos Patos no sentido sul.

Na década de 1991 a 2000, a porção do Estado que apresenta maior ocorrência situa-se entre a divisa da mesorregião noroeste e sudoeste. Referindo-se as classes 5 e 6 ocorre no Noroeste estendendo-se em direção a porção sudoeste do Estado. Esta classe aparece também no escudo Sul Riograndense (Figura 5). Nesta década a área de menor ocorrência de estiagem diminui em comparação a década de 1980 a 1990, permanecendo na porção nordeste e metropolitana e uma pequena área no estremo sul do Estado.

Na década de 2001 a 2010 a maior ocorrência de estiagem ocorre em uma faixa estreita do norte ao noroeste do estado do Rio Grande do Sul, seguindo em direção a área de Quaraí, ocorrendo ainda em duas áreas isoladas, uma abrange o entorno e a montante da barragem do Passo do Real no Alto Jacuí e a outra no extremo leste do município de Dom Pedrito na divisa com os municípios de Bagé e Lavras do Sul (Figura 6). 


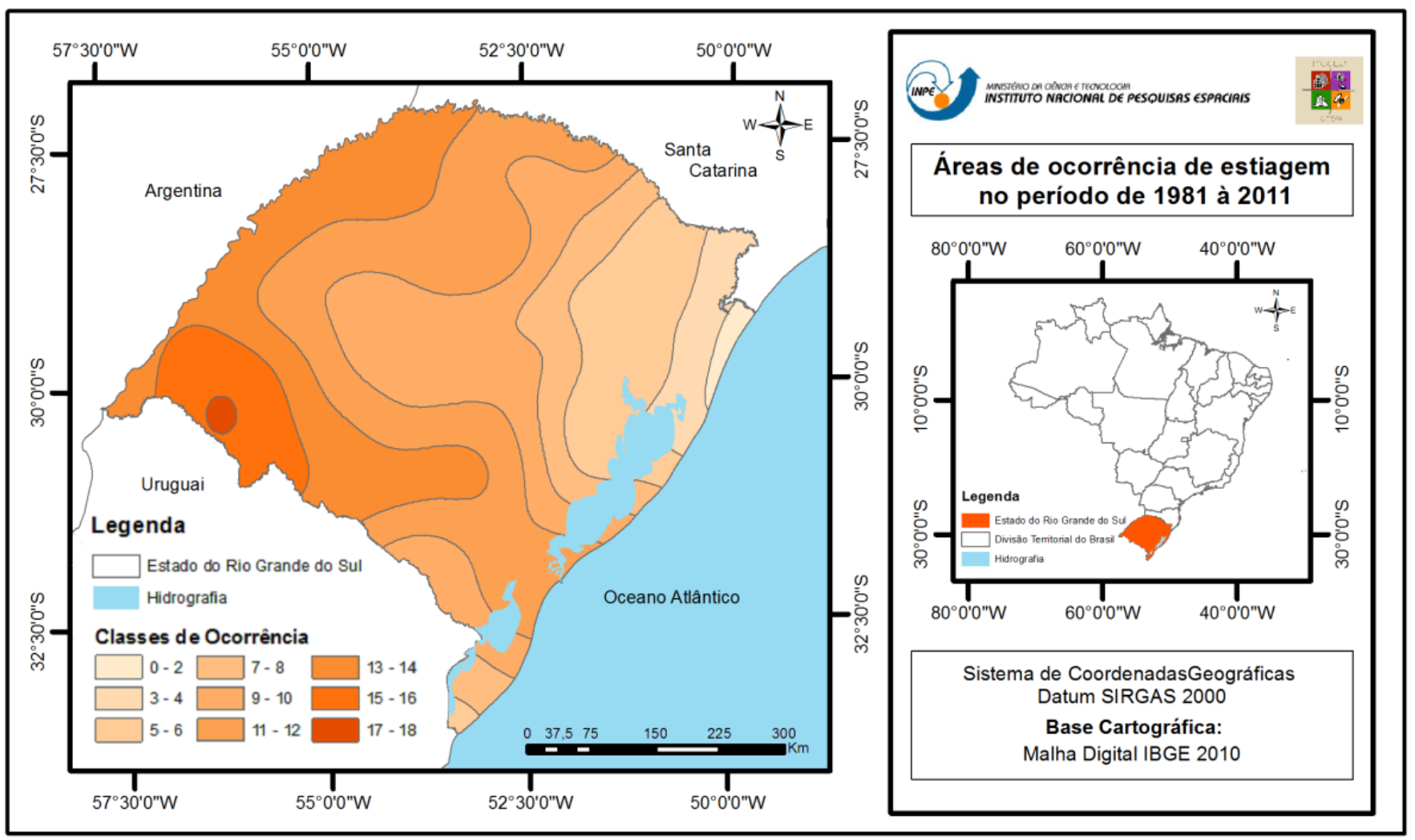

Figura 3 - Zoneamento do somatório da ocorrência de estiagem em 31 anos, no Rio Grande do Sul.

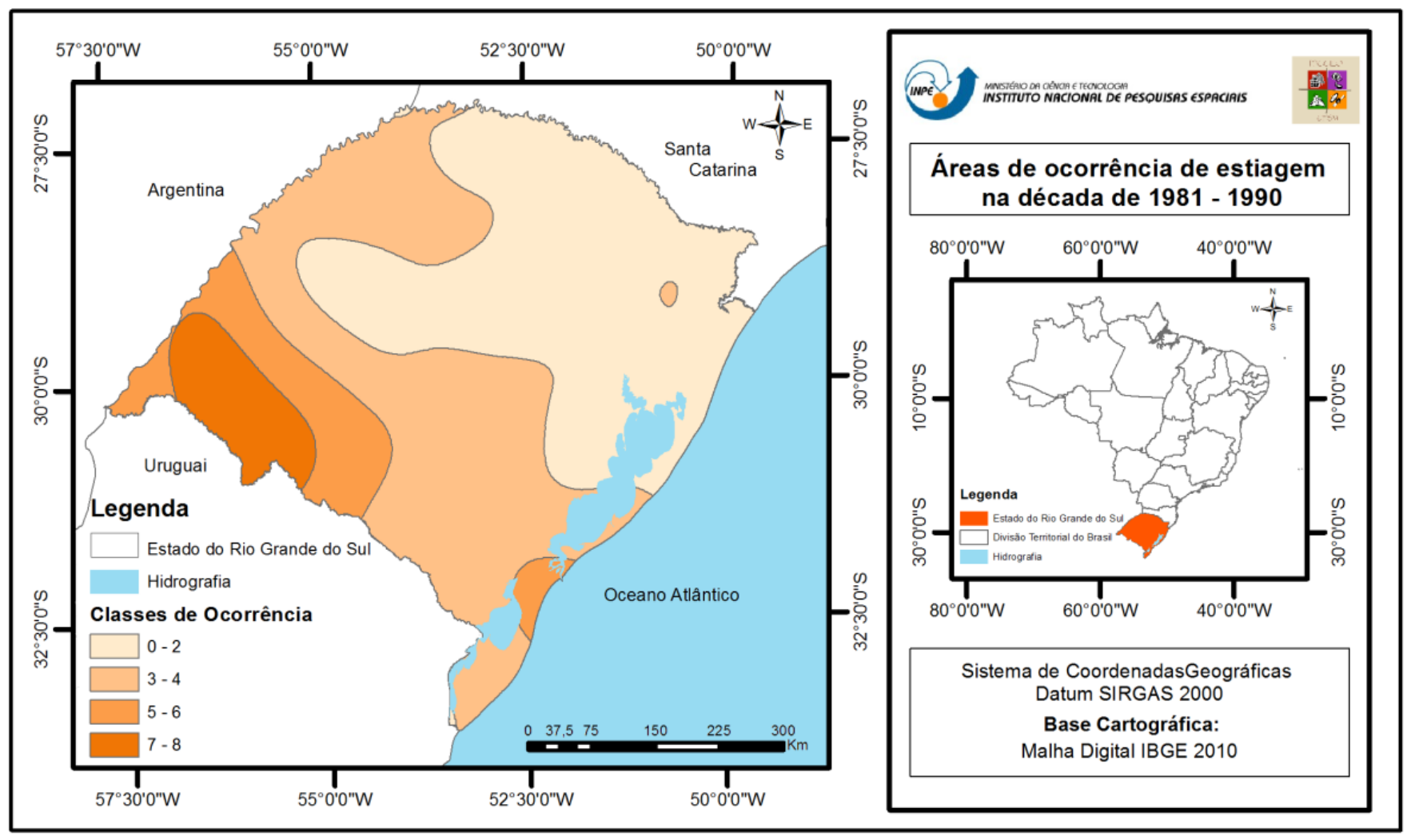

Figura 4 - Zoneamento da ocorrência de estiagem na década de 1981 a 1990, no Rio Grande do Sul. 


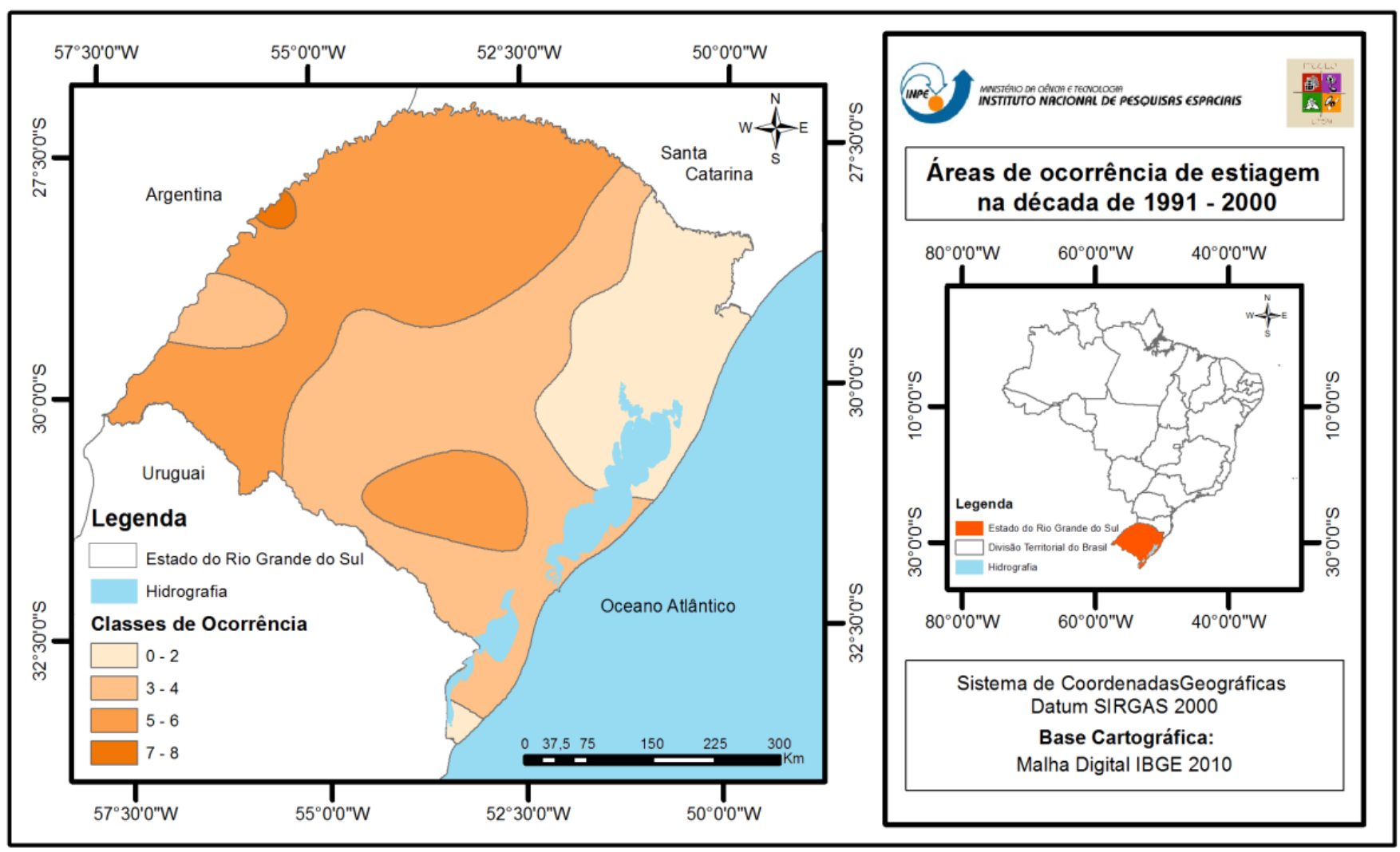

Figura 5 - Zoneamento da ocorrência de estiagem na década de 1991 a 2000, no Rio Grande do Sul.z

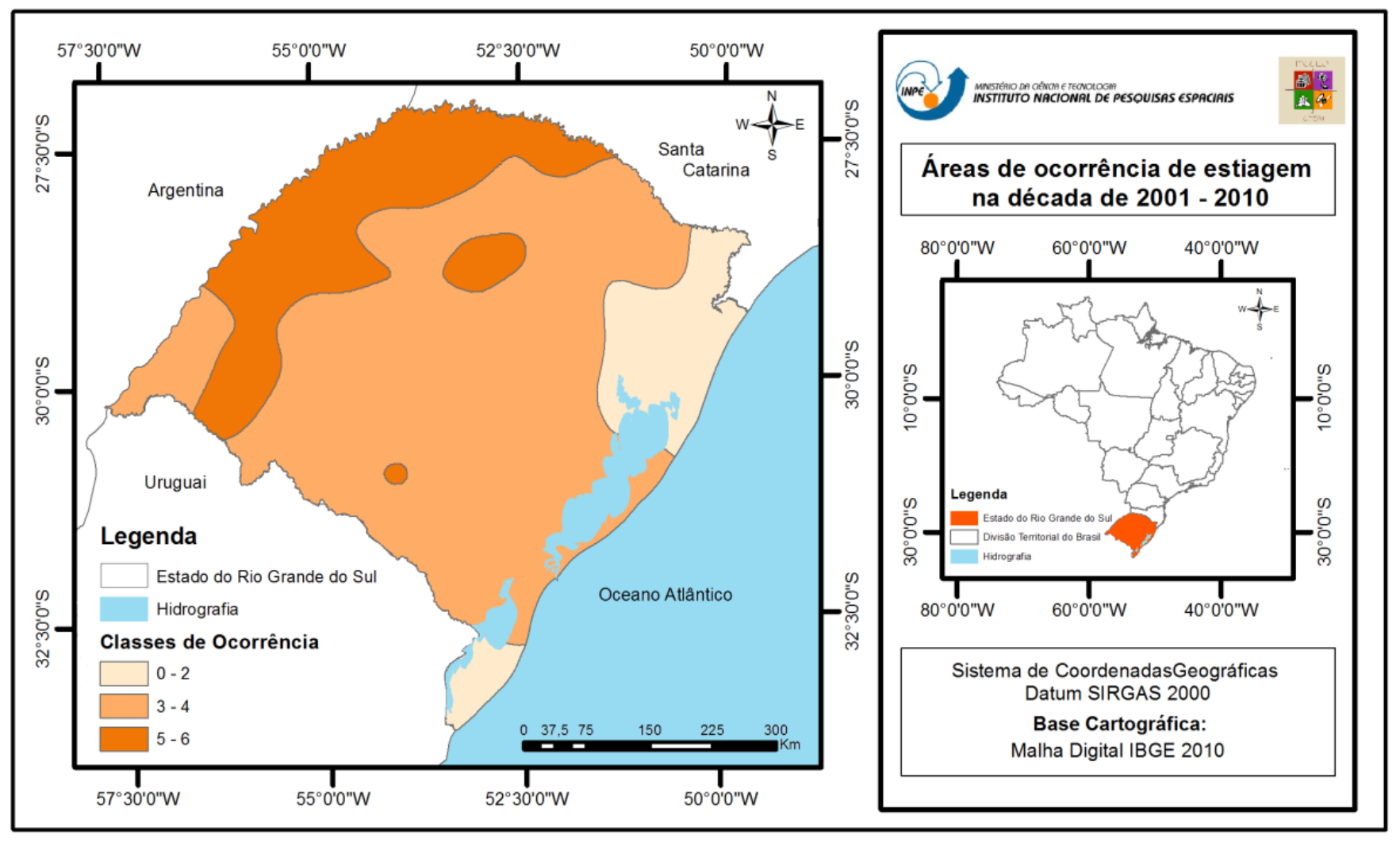

Figura 6 - Zoneamento da ocorrência de estiagem na década de 2001 a 2010, no Rio Grande do Sul. 


\section{Conclusões}

A importância de estudos voltados aos desastres naturais causados pela estiagem se deve aos registros de ocorrência de danos, principalmente no Rio Grande do Sul.

O método da Krigagem respondeu o objetivo proposto, permitindo a espacialização em áreas homogêneas, saindo de uma visão unitária por município. Pois, utilizou-se das médias locais ou tendências locais estimadas, a partir das ocorrências dos municípios vizinhos. Portanto, trouxe a visualização de grandes áreas de abrangência do fenômeno utilizando a técnica difundida em outros estudos climáticos.

As maiores ocorrências são registradas na porção Sudoeste do Estado e a área de menor de ocorrência de estiagem situa-se no litoral norte e na porção norte do Estado, bem como no rebordo do Planalto Sul Riograndense e Depressão Central seguindo a Laguna dos Patos no sentido sul. Pelo fato da porção sudoeste do Estado concentrar as áreas de maior ocorrência de estiagem merece maior atenção e preocupação das autoridades.

O conhecimento referente a espacialização e a sequência da ocorrência de estiagem possibilita, mediante planejamento e investimento, a diminuição de perdas econômicas, principalmente no setor agropecuário e, a partir disso, permite orientar a tomada de decisões das autoridades para adotar medidas mitigadoras.

Desta forma, torna-se necessário um estudo mais aprofundado dos motivos que levaram a diminuição, da classe 7 a 8 , de ocorrência de estiagem, principalmente na primeira década de análise.

\section{Referências}

ANDRIOTTI, J.L.S. Fundamentos de estatística e geoestatística. São Leopoldo: Unisinos, 2003. 165p.

BETTINI, C. Conceitos básicos de geoestatística. In: MEIRELLES, M.S.P.; CÂMARA, G.; ALMEIDA, C.M. Geomática: modelos e aplicações ambientais. Brasília, DF: Embrapa, 2007. 234 p.

CASTRO, A.L.C. et al. Manual de desastres: desastres naturais. Brasília, DF: MIT, 2003. 174 p. Disponível em: $<$ http://www.inpe.br/crs/geodesastres/ conteudo/livros/Defesa20Civil 2003 Desastres Naturais vol I.pdf $>$. Acesso em: 07 jan. 2014.

ISAAKS, E.H.; SRIVASTAVA, R.M. An introduction to applied geostatistics. New York: Oxford University Press, 1989.

FELGUEIRAS, C.A. Modelagem Ambiental com tratamento de incertezas em sistemas de informação geográfica: o paradigma geoestatístico por indicação. 1999. 213 f. Tese (Doutorado em Computação Aplicada) - Instituto Nacional de Pesquisas Espaciais, São José dos Campos, 2001. Disponível em: $<$ http://mtc-m05.sid.inpe.br/col/sid. inpe.br/deise/2001/08.03.12.35/doc/publicacao.pdf $>$. Acesso em: 22 jan. 2014.

FURLAN, M.C.; LACRUZ, M.S.P.; SAUSEN, T.M. Vulnerabilidade Socioeconômica à Ocorrência de Eventos Extremos: Proposta Metodológica. In: SIMPÓSIO BRASILEIRO DE SENSORIAMENTO REMOTO, 15., 2011, Curitiba. Anais eletrônicos... Curitiba: INPE, 2011. Disponível em: $<$ http://www. dsr.inpe.br/sbsr2011/files/p1542.pdf $>$. Acesso em: 07 jan. 2014.

GROSS, J.A.; REIS, J.T.; SAUSEN, T.M.; Avaliação Socioeconômica dos Municípios Afetados Pela Estiagem no Rio Grande do Sul de 2000 a 2010. In: CONGRESSO BRASILEIRO SOBRE DESASTRES NATURAIS, 1., 2012, Rio Claro. Anais eletrônicos... Rio Claro: UNESP, 2012. Disponível em: < $\underline{\text { http:// }}$ www.inpe.br/crs/geodesastres/conteudo/ publicacoes/Avaliacao Socioeconomica dos Municipios Afetados Pela Estiagem no Rio Grande do Sul de 2000 A 2010.pdf $>$. Acesso em: 09 jan. 2014.

KOBIYAMA, M.; MICHEL, G.P.; GOERL, R.F. Relação entre desastres naturais e floresta. Revista Geonorte. Manaus, ano 3, n. 6, jul/ nov. 2012. Disponível em : <http://www. revistageonorte.ufam.edu.br/attachments/article/7/ Rela\%C3\%A7\%C3\%A3o\%20entre\%20desastres\%20 naturais \%20e\%20floresta.pdf $>$. Acesso em: 15 jan. 2014.

PONCE, V.M. Drought. PONCE, V.M. Three issues of sustainable management in the Ojos Negros valley, Baja California, México. Baja California - México, 2002. Disponível em: http://ponce.sdsu. edu/threeissues.html. Acesso em: 20 de jan 2014.

RECKZIEGEL, B.W. Levantamento dos desastres desencadeados por eventos naturais adversos no estado do Rio Grande do Sul no período de 1980 a 2005. 2007. 370 f. Dissertação (Mestrado em Geografia) - Universidade Federal de Santa Maria, Santa Maria, 2007.

REIS, J.T. et al. Avaliação dos Desastres Naturais Ocorridos no Rio Grande do Sul de 2007 a 2011. In: CONGRESSO BRASILEIRO SOBRE DESASTRES NATURAIS, 1., 2012, Rio Claro. Anais eletrônicos... Rio Claro: UNESP, 2012. Disponível em: $<$ http://www.inpe.br/crs/geodesastres/ conteudo/publicacoes/Avaliacao dos desastres 
naturais ocorridos no Rio Grande do Sul de 2007 a 2011.pdf $>$. Acesso em: 09 jan. 2014.

SAITO, S.M. et al. Avaliação dos desastres naturais ocorridos no Rio Grande do Sul em 2008. In: SIMPÓSIO BRASILEIRO DE SENSORIAMENTO REMOTO, 15., 2011, Curitiba. Anais eletrônicos... Curitiba: INPE, 2011. Disponível em: $<$ http://www. dsr.inpe.br/sbsr2011/files/p0840.pdf > . Acesso em: 13 jan. 2014.

SILVA, S.A.B. et al. Aplicação da Geoestatística no Desenvolvimento de uma Base de Dados Climatológicos Para Uso no Modelo de Transferência Radiativa Brasil - SR. In: SIMPÓSIO BRASILEIRO DE SENSORIAMENTO REMOTO, 11., 2003, Belo Horizonte. Anais eletrônicos... Belo Horizonte: INPE, 2003. Disponível em: $<$ http://sonda.ccst.inpe.br/publicacoes/eventos/ XISBSR 2003 BH 11294 Sheila etal.pdf>. Acesso em: 15 jan. 2014. 